\title{
Community-Based Ecotourism for Assessment Potential and Planning at Phou Khao Khouay National Protected Area, Lao Pdr
}

\author{
Boonthavy Douangphosy ${ }^{1}$, Chen Hong Han', Cui Kang Ping²
}

\author{
${ }^{1}$ School of Water Resources Environmental Engineering, China University of Geosciences, Beijing 100083, China \\ ${ }^{2}$ School of Resources and Environmental Engineering, Hefei University of Technology, Hefei 230009, China
}

\begin{abstract}
This study used an area assessment technique and local community interviews as the key tools to achieve the three study objectives: to assess the potential of the site for ecotourism establishment; to examine the local needs and readiness of the community to participate in the ecotourism management; and to examine factors affecting the opinions of local community participation plan of ecotourism. To assess these three main objectives, 194 respondents were selected and interviewed. The responses were then analyzed statistically using percentage, maximum, and mean values. In addition, the hypotheses were developed and tested using the chi-square analysis technique in order to determine relationships between the variables. The site assessment using four ecotourism criteria showed $85 \%$, which falls into an "excellent" category of ecotourism potential. In addition, the interviews to promote local community participation in the ecotourism plan were also used to assess the local needs and readiness. The results tabulated from the interviews show that the local needs of ecotourism were of 3.44, showing that there was an urgent need among the local community, while the readiness to respond to this need was 2.69; the local needs of tour guides was 3.51, while the readiness was 3.03; the local needs for the services was 3.19 , while the readiness was 2.05. Furthermore, the study determined that the need for government support in four activities was at the medium level. The results showed the home stays was an average of 2.00 , the tour guides was 2.00 , the infrastructure development was 2.01 , and the provision of goods and services was 2.00 . Finally, the results of hypothesis testing on statistical significance at the 0.05 level indicated no significant difference in responses based on the gender and the readiness of the services to provide tour guides, age and the needs of the services to provide accommodation, age and the needs and readiness of the services to provide tour guides, occupation and the needs of the services to provide accommodation, income and the readiness of the services to provide accommodation.
\end{abstract}

Keywords: assessing potential, ecotourism, local community participation, Laos

\section{INTRODUCTION}

Phou Khao Khouay National Protected Area (PKK-NPA) is a forest with long history that plays an essential part in the Lao economy. Therefore, the government of Lao People's Democratic Republic (Lao PDR) declared it to be a national protected area in 1993 with a primary purpose to conserve species of plants and wildlife, and the natural condition of unique natural sightseeing activities. (Conservation Division, 2001). But the management of the tourist attractions of each type of assessment has not been a source of quality standards, and the assessment of the needs and readiness of the community-based ecotourism potential with 4 elements: (1) the potential to become an ecotourism, (2) management of the utilization of area in order to achieve sustainability, (3) management to educate and create awareness, and (4) the participation of communities in ecotourism activities (Environmental Research Institute, 2005). For conservation tourism, there are four elements such as the awareness about the natural conservation and environment, the satisfaction of a tourist, the participation of local communities and the distribution of income located in and around the tourist attractions (Forest Research Center, 1995). However, forestry management, participation in accordance with the principles of community forestry, is the opportunity to expose local community participation to a sustainable forest

This article is published under the terms of the Creative Commons Attribution License 4.0

Author(s) retain the copyright of this article. Publication rights with Alkhaer Publications.

Published at: http://www.ijsciences.com/pub/issue/2015-03/

Article Number: V420150301; Online ISSN: 2305-3925; Print ISSN: 2410-4477 
production which creates economic benefits to the communities and positive returns to the nature.

Planning process for ecotourism in conservation areas consists of nine processes including: scoping plan area, goals target data collecting, data analysis, compounding plan outline, presentation plan and selected right choice, implementation, monitoring and evaluation, and improvement plan (Datchanee, 2006). In response to the Govrrnement's Strategic Plan 2020, PKK-NPA in Bolikhamxa Province, Lao PDR, is chosen to study for the feasibility of the ecotorism potential site to be used as guideline for other ecotourism sites across the province (Department of Information, Culture and Tourism, 2007).

The objectives of this research to assess the potential of the area for ecotourism establishment, to examine the local needs and readiness of the community to participate in the ecotourism management; and to examine factors affecting the opinions of local community participation plan of ecotourism. Scope of the study to evaluate the potential of community-based ecotourism, needs assessment and readiness of home stays services; tour guides services and readiness for event services for tourists. The feedback from monitoring allows researchers to hypothesize that genders, educations, ages, educations, occupations, incomes, needs and readiness for the home stay services, needs and readiness for tour guides services and needs and readiness for event services for tourists.

\section{MATERIALS AND METHODS}

The equipment used in this study consists of the map, the computer and program, stationary filed, the assessment quality standard form of ecotourism area and interview forms about the opinions of community plan to promote ecotourism area by local community participation in the study area at Phonngam, Yangkeua, Hatkai and Houayleuk Village, Thapabad District, Bolikhamxai Province, located towards the south of Vientiane capital approximately 90 kilometers along the national road $13^{\text {th }}$. The total area for these four villages covers 3174.02 hectares, between the coordinates latitude $18^{\circ} 22^{\prime} 18^{\prime \prime} \mathrm{N}$ and longitude $103^{\circ} 40^{\prime} 00^{\prime \prime} \mathrm{E}$ with height from these a level approximately 155.13 meters.

The study on community-based ecotourism for assessment potential and planning at PKK-NPA is the study of survey and interview as a data collection procedure is performed as follows.

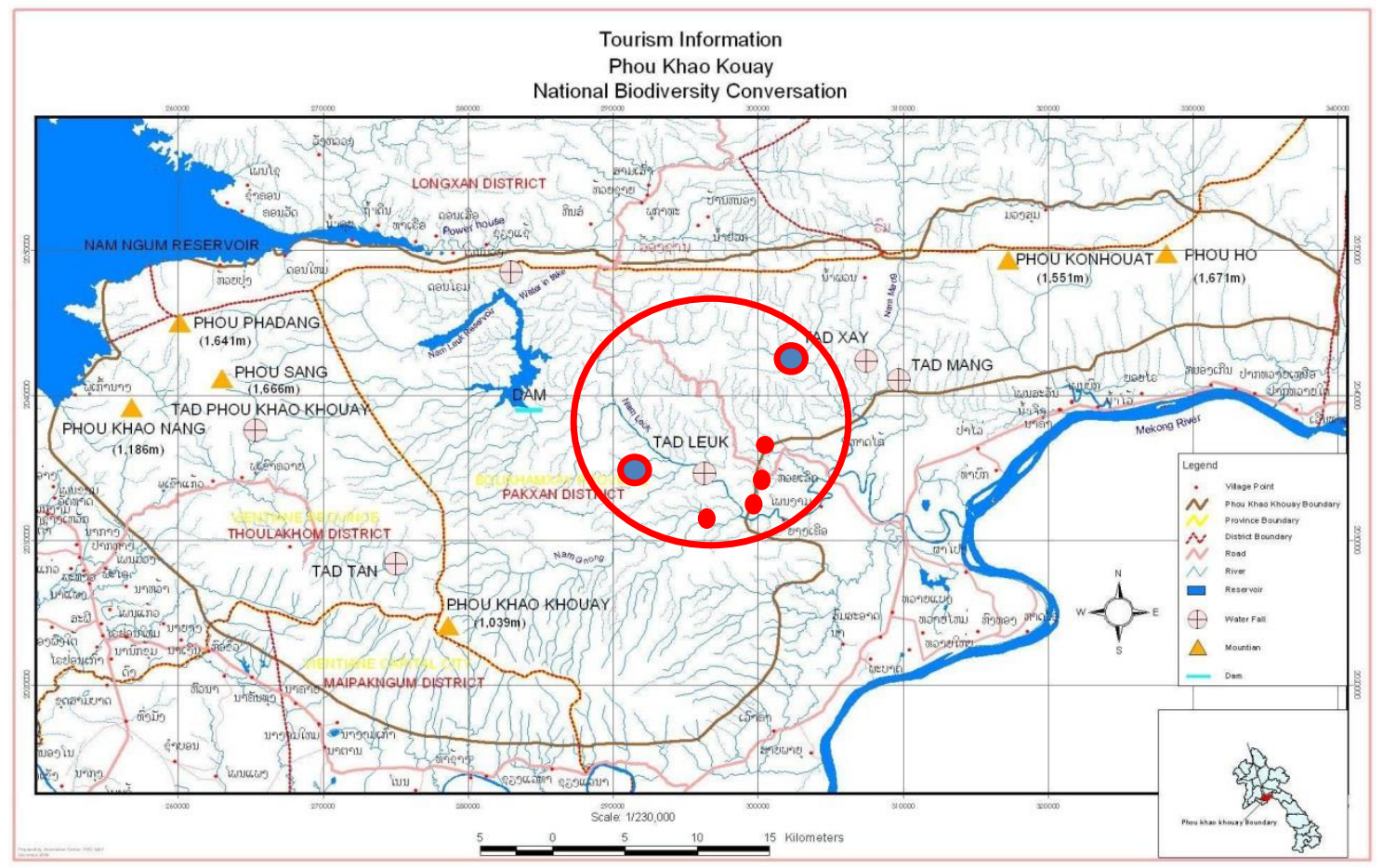

Figure 1: Location of the research area 


\subsection{Assessment the Potential of Ecotourism Area}

Assessment standard quality ecotourism area of PKK-NPA as the participating community in composed $\mathrm{t} \mathrm{W}$ o major standardize qualities: (1) Location of the ecotourism and assessing the standardize quality of ecotourism site. For the second major, it is combining of fo u r parts: (1) assessment standardizes quality of ecotourism attraction, (2) management of the utilization of area to achieve sustainability, (3) management to educate and create awareness and (4) local community participation. The ecotourism activities are conducting by survey on part field patrol and using assessment methods agreeing to researchers who have previously considered, (Environmental Research Institute, 2005),, interviewing is shown by target group in latency ecotourism attraction manner and using points giving technique. The points calculating and assigning standardize quality ecotourism attraction manner specification level are detailed as below.

\section{Scoring Methods}

Scoring methods include two ways: (1 ) the ratings considering that ecotourism has met with most of the above indicators and a score of this rating ranges from 0 to 5 , (2) the ratings considering the ecotourism has not met the above indicators and score is choosing 0 or 1 , The both ways mark the same by using [ ] and the weight is a value that has been set up, which was equal to 2 and 1, using the value depending on importance of each sub indicator.

\section{Determining Level Standard Quality of Ecotourism Area}

The specification of standard quality level of ecotourism attraction will be compared with standard level. In general, it is below par if the level is less than 50, moderate if 50-60, good if 61-70, excellent if $71-80$, and very excellent if more than 81 .

\subsection{Needs and Readiness of the Community Plan to Promote Ecotourism Participatory}

The opinion study of the community plan to promote ecotourism attraction in 4 villages in this community has emphasized studying on needs and the readiness and managed services in order to apply the results from the study as a guide to community-based ecotourism planning in the next step. The composition of the questionnaire used in the study consisted of two steps. (1) The status of the interviewees and the household which; occupation, income, forest utilization and (2 ) interview the opinion on community needs and readiness to be participating in ecotourism administration.

\section{Research Tools}

This research is a qualitative research. The data were collected using a questionnaire with both closed-ended and open-ended questions as follows:

1. The draft survey questions within the scope of the objectives and content of research given to the question as much as possible. Then check the accuracy of answers that are consistent with the objectives of the research.

2. Put to the test questionnaires to obtain the data collection completely follows as objectives of studies.

3. To adapt the questionnaires where appropriate and apply for a next better data collection.

\section{Selecting Samples to Study the Exception of Community Ecotourism Plan}

The group of people whom may concern in latency assessment of ecotourism on the community participation are the representatives from fou $\mathrm{r}$ local villages residing around the reservation national area , there are 399 households, and then conduct sample separation groups by using the technique of the random sampling to divide (Stratified Random Sampling); from each random group, sub-groups are being formed into leader community group, leader tour group, handicraft group, community contributing fund group, group of advantage users from the forest, housekeeper group, etc. Then randomization is conducted again from each sampling group to represent the households according to the suitability from the people sampling studies process, sample scope of studies is 194 households, which can seek different sample appropriate scope by using table (Krejcie and Morgan, 1970).

\subsection{Data Analysis}

After the collection of data of two different forms; primary data and the secondary data, the researchers recheck the questionnaires correctness and completeness then keep going on do downing password and evaluate by using computer systems, a programming, to explain and analyse data by consuming statistics description with the data collected, enumerating statistics calculation, for example: maximum, percentage, average, and using statistics quantity manner by hypothesis test for seeking the relation of the variable by (chi-square) assigned confidence value with $0.0 \quad 5$ level in hypothesis test for drawing the relationship

\section{RESULTS AND DISCUSSION}

The results of the research study conducted to evaluate the potential of ecotourism participatory 
were divided into four sections below.

\subsection{Evaluate the Potential of the Ecotourism Area.}

Assessing the quality ecotourism area of PKK-NPA by using four sets of indicators for quality ecotourism principles of ecotourism: the potential score for ecotourism area with the score of 34 points, management of the utilization of forest area to achieve sustainability with the score of 11 points, management to educate and create awareness with the score of 10 points, and the involvement of the community in activities with the score of 14 points. Therefore, the assessment attractions considering the main components using all the indicators studying the potential ecotourism of PKK-NPA yields $6 \quad 9$ percentages. This was considered to be the standard in ecotourism is good level, referring to assessment standardize quality of ecotourism attraction handbook (Environmental Research Institute, 2005). These natural resources have not been developed into any tourist activities. In cases where the responsibility for that area who wish to know whether their area is suitable or has the potential to be developed as ecotourism or not, it can be evaluated to assess the nature area. The only component assesses the potential for ecotourism area as a source consists of 4 sub-indices and the results of the evaluation index score was 34 or 85 percentages of the index shows that the potential for ecotourism area is PKK-NPA has excellent potential.

\subsection{The Status of the Interviewees and Household, Occupation, Income and Forest Utilization.}

The details of studying status, occupation, income, and forest utilization of four local villages to promote ecotourism at PKK-NPA, are as follows.

\section{Demographic Characteristics}

Reviewing of people character in four local villages' communities comprised: gender, age, education level. Some details from educating 194 sample households shown that, 72.00 percentages are males and the females are 28.00 percentages, almost of them are over 45 years old, and covering by 64.67 percentages, 24.00 percentages are the age between 25-34 years old, aging between 35-44 years old is 22.67 percentages and lower than 24 years old is 6.67 percentages. In additions, the sampled households with elementary education cover 48.00 percentages, while the illiterate group 22.67 percentages, the lower secondary school education level is 21.33 percentages and upper secondary school education is 6.67 percentages, in the nutshell, almost all of the sampled households lack education.

\section{Economical and Societal Character}

Sample groups' main occupations are mostly farmers forming57.33 percentages of the group, next smaller

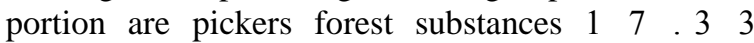
percentages, others occupation is 9.33 percentages, sellers and workers amount to 8.00 percentages. The main source of income of the sampled households comes from agriculture in growing plants and livestock rearing, However, analysed data ranked and presented that, group of sample people's majority income is less than 2,500,000 Kip per year, matching 50.67 percentages, next lower ration are earning between 2,525,000-5,000,000 Kip per year, sorting 34.67 percentages, and over 5,025,000 Kip per year of earner group is 14.67 percentages.

\section{Utilization of Forest Resources}

Due to the dependence on forest of four local villages from diverse sorts of forests, there are different proportions as following: the forest proportion bouncing to household incomes standing of 17.33 percentages, by separate to forest consumption remaining of 15.52 percentages, forest vending is 1.81 percentages. However, the forest annual total value is $400,486,000 \mathrm{Kip}$ per year, meanwhile, if all incomes of dependence on forest were determined and detected into: 5 types of firewood equals $2,335.04$ cubic meter quantities, total price tag is $17,512,750 \mathrm{Kip}$, and equals 17.49 percentages. 4 kinds of usage woods equals 40 cubic meter quantities, $5,250,000 \mathrm{Kip}$ and equals 5.24 percentages. 12 kinds of vegetable brush, 6,636 kilogram quantities, total price tag is $1,659,000 \mathrm{Kip}$, 16.57 percentages. 9 kinds of mushrooms equals 27,280 kilogram quantities, total price tag is $34,100,000 \mathrm{Kip}$ and equals 34.06 percentages. 6 kinds of eating insect equals 2,4000 kilogram quantities, total price tag is 7,200,000 Kip and equals 57.19 percentages. 5 types of shooting bamboo equal 16,000 kilogram quantities, 4,000,000 Kip and equal 4.00 percentages. And 13 kinds of other equals 4,552 kilogram quantities, total price tag is $15,468,750 \mathrm{Kip}$ and equals 15.45 percentages.

\subsection{Interview the Community Opinion on the Plan to Promote Ecotourism}

Interview the opinions of the local community participatory to plan to promote ecotourism area. An important factor, which consists of four parts including the need and readiness: (1) provide accommodation services, (2) provide tour guides services, (3) provide tourists services and (4) the needs assistance from the government in helping activities, there is the detail as follows:

Needs and Readiness of the Services to Provide 


\section{Accommodation}

The result of opinions in interviews for needs in the accommodation services are included by 3 sub-indicators (1) the community has needs for the tourists to stay overnight at the highest level, (2) to provide accommodations services to tourists at the highest level and (3) the accommodations activities mounting into commercial incomes services were all needed as a highest level and in summarizing of all sides needs average was highest level of availability of the accommodation services.

An interviews for the accommodation services consists of five sub indicators (1) your household has the potential to provide tourist accommodation at the highest level, (2) you can build accommodation for visitors at the medium level, (3) you can cooking for tourists at the high level, (4) you are able to communicate with tourists in the country at the highest level and (5) you can communicate with foreign tourists at the low level and in summarizing of all sides readiness average was the accommodations service of the residential as in higher motivated level.

\section{Needs and Readiness of the Services to Provide Tour Guides}

Needs to be available in the tour guide services have three sub-indicators: (1) your community needs to have a professional tour guide services at the highest level, (2) you have a family members to be a tour guide services at the highest level and (3) professional guides will provide you occupations with more income at the highest level and the summarizing of all sides needs average was high level.

The readiness to provide tour guide services have five sub indicators: (1) members of your household have the potential a tour guide services at the high level, (2) you have knowledge of hiking at high level, (3) you have any knowledge about plants, as well as high level, (4) you have knowledgeable about wildlife, as well as high level, (5) you have knowledgeable about the history of the area as well as high level, and (6) you have any knowledge about the livelihood and career of the community as well as high level and the average value of the availability of the service into tour guides at the level.

\section{Needs and Readiness of the Services for Tourists}

Needs for the tourists goods in services has three sub indicators: (1) your community needs to sell foods and souvenirs to tourists at the highest level, (2) you need of their community as to be careers on trade to serve the tourist in the highest level, (3) and the commercial occupations to the tourists will be increasing of incomes in higher level, The average value of all needs in providing a high level.

Readiness to sale goods services for tourist's consumption has fiv e sub indicators: (1) you are readiness to sale food for tourist's services in higher level; (2) you are readiness to sale souvenir for tourist in medium level, (3) you are readiness to sale of goods consumption in the medium level, (4) you are readiness to sale handmade products from community forest in the medium level, and (5) you readiness to sale others goods in the smaller level. The average value of all readiness services for goods selling to the tourist was in the medium level.

\section{Need for Assistance from the Government to Helping Activities}

The requirement supporting about the accommodations consists of five sub indicators, (1) the need of foundation to establish commonly the tourist a residence investment was taken of high level, (2) loan supporting needed for tourists homestay building was taken of medium level, (3) training on homestay services in the medium level, (4) management and financial accounting at a low level, and (5) allowing a business license patio tent at a low level. The average value of these sub indicators supports the accommodations services in the medium level.

The needs for support for tours guide services was divided into fiv e sub indicators: (1) Training in foreign languages at a high level, (2) Training in nature guide at a high level, (3) Training in first aid in the medium level, (4) Training in bringing tourists to seeing orchid in the medium level, and (5) Training in bringing tourists to seeing bird at this low level. The average value of all needs supports in the medium level.

The needs for support the basic construction based on five sub indicators: (1) creating the asphalt road to the Tatloek and Tatxay waterfall at the highest level, (2) establishing of water supplied system in a village was selected on high level, (3) creating waste substance reduction system was interested in a low level, (4) the study of the nature trail and (5) the tourist checking checkpoints were pointed on a low level. The averaging requirement of basic construction support was positioned on a medium level.

The commercial supporting requirement were related to $\mathrm{f} \mathrm{i} \mathrm{v} \mathrm{e} \mathrm{sub} \mathrm{indicators:} \mathrm{(1)} \mathrm{to} \mathrm{create} \mathrm{the} \mathrm{tourist}$ information centre as high level, (2) foods stores investment as medium level, (3) souvenir stores investment as medium level, (4) the mess media and 
marketing management training at the a medium level, and (5) food service and sale souvenir as a low level. The average commercial requirement support side was on medium level.

\subsection{Factors affecting the community feedback on the plan to promote ecotourism.}

Economic and social relationship between factors analysis with all independent variables include: gender, age, education level, occupation, and income; and dependent variables include: needs and readiness of the services to provide accommodation, needs and readiness of the services to provide tour guides and needs and readiness of the services for tourists. The hypotheses were developed and tested using the Chi-square analysis technique in order to determine relationships between variables and total has 15 hypothesizes as described below

Hypothesis1: The relationship between gender and the needs and readiness of the services to provide accommodation.

Gender has no significant difference in responses based on needs of the services to provide accommodation by the value $\chi^{2}=1.428 \mathrm{~ns}$ and p-value $=0.187$ and gender has no significant difference in responses based on readiness of the services to provide accommodation by the value $\chi^{2}=$ $0.863 \mathrm{~ns}$ and $\mathrm{p}$ - value $=0.347$ which is higher than testing on statistical significance at the 0.05 level. Thus, both needs and readiness of the services to provide accommodation was rejected the first hypothesis.

\section{Hypothesis 2: The relationship between gender and the needs and readiness of the services to provide tour guides.}

Gender has no significant difference in responses based on needs of the services to provide tour guide by the value $\chi^{2}=0.587 \mathrm{~ns}$ and $\mathrm{p}$-value $=0.400$ which is higher than testing on statistical significance at the 0.05 level Thus, the needs of the services to provide tour guide was rejected the second hypothesis and gender has significant difference in responses based on readiness of the services to provide tour guide by the value $\chi^{2}=13.880 \mathrm{~ns}$ and $\mathrm{p}$-value $=0.000^{* *}$ which is lower than testing on statistical significance at the 0.05 level. Thus, the readiness of the services to provide tour guide was accepted the second hypothesis.

Hypothesis 3: The relationship between gender and the needs and readiness of the services for tourists.

Gender has no significant difference in responses based on needs of the services for tourist by the value $\chi^{2}=1.477 \mathrm{~ns}$ and $\mathrm{p}$-value $=0.240$ and gender has no significant difference in responses based on readiness of the services for tourist by the value $\chi^{2}=2.225 \mathrm{~ns}$ and $\mathrm{p}$ - value $=0.080$ which is higher than testing on statistical significance at the 0.05 level. Thus, both the needs and readiness of the services for tourist was rejected the third hypothesis.

\section{Hypothesis 4: The relationship between age and the needs and readiness of the services to provide accommodation.}

Age has significant difference in responses based on needs of the services to provide accommodation by the value $\chi^{2}=9.137 \mathrm{~ns}$ and $\mathrm{p}$-value $=0.013^{*}$ which is lower than testing on statistical significance at the 0.05 level. Thus, the needs of the services to provide accommodation was accepted the fourth hypothesis and age has no significant difference in responses based on readiness of the services to provide accommodation by the value $\chi^{2}=13.760 \mathrm{~ns}$ and p-value $=0.080$ which is higher than testing on statistical significance at the 0.05 level. Thus, the readiness of the services to provide accommodation was rejected the fourth hypothesis.

Hypothesis 5: The relationship between age and the needs and readiness of the services to provide tour guides.

Age has significant difference in responses based on needs of the services to provide tour guide by the value $\chi^{2}=15.233 \mathrm{~ns}$ and $\mathrm{p}$-value $=0.000^{* *}$ and age has significant difference in responses based on readiness of the services to provide tour guide by the value $\chi^{2}=17.640 \mathrm{~ns}$ and $\mathrm{p}$ - value $=0.013 *$ which is lower than testing on statistical significance at the 0.05 level. Thus, both the needs and readiness of the services to provide tour guide was accepted the fifth hypothesis.

Hypothesis 6: The relationship between age and the needs and readiness of the services for tourists.

Age has no significant difference in responses based on needs of the services for tourist by the value $\chi^{2}=$ 1. $242 \mathrm{~ns}$ and $\mathrm{p}$-value $=0.480$ and age has no significant difference in responses based on readiness of the services for tourist by the value $\chi^{2}=9.857 \mathrm{~ns}$ and $\mathrm{p}$ - value $=0.453$ which is higher than testing on statistical significance at the 0.05 level. Thus, both the needs and readiness of the services for tourist was rejected the sixth hypothesis.

Hypothesis 7: The relationship between education and the needs and readiness of the services to provide accommodation. 
Education has no significant difference in responses based on needs of the services to provide accommodation by the value $\chi^{2}=4.603 \mathrm{~ns}$ and $\mathrm{p}$-value $=0.347$ and education has no significant difference in responses based on readiness of the services to provide accommodation by the value $\chi^{2}=$ $15.151 \mathrm{~ns}$ and $\mathrm{p}$-value $=0.053$ which is higher than testing on statistical significance at the 0.05 level. Thus, both the needs and readiness of the services to provide accommodation was rejected the seventh hypothesis.

Hypothesis 8: The relationship between education and the needs and readiness of the services to provide tour guides.

Education has no significant difference in responses based on needs of the services to provide tour guide by the value $\chi^{2}=4.536 \mathrm{~ns}$ and $\mathrm{p}$-value $=0.107$ and education has no significant difference in responses based on readiness of the services to provide tour guide by the value $\chi^{2}=9.523 \mathrm{~ns}$ and $\mathrm{p}$-value $=0.360$ which is higher than testing on statistical significance at the 0.05 level. Thus, both the needs and readiness of the services to provide tour guide was rejected the eighth hypothesis.

Hypothesis 9: The relationship between education and the needs and readiness of the services for tourists

Education has no significant difference in responses based on needs of the services for tourist by the value $\chi^{2}=9.750 \mathrm{~ns}$ and $\mathrm{p}$-value $=0.453$ and education has no significant difference in responses based on readiness of the services for tourist by the value $\chi^{2}=$ $8.693 \mathrm{~ns}$ and $\mathrm{p}$-value $=0.360$ which is higher than testing on statistical significance at the 0.05 level. Thus, both the needs and readiness of the services for tourist was rejected the ninth hypothesis.

\section{Hypothesis 10: The relationship between occupation and the needs and readiness of the services to provide accommodation.}

Occupation has no significant difference in responses based on needs of the services to provide accommodation by the value $\chi^{2}=4.579 \mathrm{~ns}$ and p-value $=0.520$ and occupation was no significant difference in responses based on readiness of the services to provide accommodation by the value $\chi 2=$ $18.170 \mathrm{~ns}$ and $\mathrm{p}$-value $=0.107$ which is higher than testing on statistical significance at the 0.05 level. Thus, both the needs and readiness of the services to provide accommodation was rejected the tenth hypothesis.

Hypothesis 11: The relationship between occupation and the needs and readiness of the

\section{services to provide tour guides.}

Occupation has no significant difference in responses based on needs of the services to provide tour guide by the value $\chi^{2}=2.599 \mathrm{~ns}$ and $\mathrm{p}$-value $=0.453$ and occupation has no significant difference in responses based on readiness of the services to provide tour guide by the value $\chi^{2}=5.139 \mathrm{~ns}$ and $\mathrm{p}$-value $=0.560$ which is higher than testing on statistical significance at the 0.05 level. Thus, both the needs and readiness of the services to provide tour guide was rejected the eleventh hypothesis.

\section{Hypothesis 12: The relationship between occupation and the needs and readiness of the services for tourists}

Occupation has significant difference in responses based on needs of the services for tourist by the value $\chi^{2}=9.150 \mathrm{~ns}$ and $\mathrm{p}$-value $=0.013^{*}$ which is lower than testing on statistical significance at the 0.05 level Thus, the needs of the services for tourist was accepted the twelfth hypothesis and occupation has no significant difference in responses based on readiness of the services for tourist by the value $\chi^{2}=$ $2.205 \mathrm{~ns}$ and p-value $=0.347$ which is higher than testing on statistical significance at the 0.05 level. Thus, the readiness of the services for tourist was rejected the twelfth hypothesis.

Hypothesis 13: The relationship between income and the needs and readiness of the services to provide accommodation.

Income has no significant difference in responses based on needs of the services to provide accommodation by the value $\chi^{2}=0.574 \mathrm{~ns}$ and p-value $=0.560$ which is higher than testing on statistical significance at the 0.05 level Thus, the needs of the services to provide accommodation was rejected the thirteenth hypothesis and income was significant difference in responses based on readiness of the services to provide accommodation by the value $\chi^{2}=6.513 \mathrm{~ns}$ and $\mathrm{p}$-value $=0.027^{*}$ which is lower than testing on statistical significance at the 0.05 level. Thus, the readiness of the services to provide accommodation was accepted the thirteenth hypothesis.

Hypothesis 14: The relationship between income and the needs and readiness of the services to provide tour guides.

Income has no significant difference in responses based on needs of the services to provide tour guide by the value $\chi^{2}=3.062 \mathrm{~ns}$ and $\mathrm{p}$-value $=0.147$ and income has no significant difference in responses based on readiness of the services to provide tour guide by the value $\chi^{2}=1.061 \mathrm{~ns}$ and $\mathrm{p}$-value $=0.253$ 
which is higher than testing on statistical significance at the 0.05 level. Thus, both the needs and readiness of the services to provide tour guide was rejected the fourteenth hypothesis.

\section{Hypothesis 15: The relationship between income and the needs and readiness of the services for tourists}

Income has no significant difference in responses based on needs of the services for tourist by the value $\chi^{2}=0.717 \mathrm{~ns}$ and $\mathrm{p}$-value $=0.253$ and income has no significant difference in responses based on readiness of the services for tourist by the value $\chi^{2}=9.102 \mathrm{~ns}$ and $\mathrm{p}$-value $=0.227$ which is higher than testing on statistical significance at the 0.05 level. Thus, both the needs and readiness of the services for tourist was rejected the fifteenth hypothesis.

\section{RESULT}

Participatory assessment of ecotourism potential in PKK-NPA has good level as the value of the estimated is 69 percent of the references to guide the assessment of quality standards that ecotourism. As for the natural resources, there is no action on tourism or tourism activities to assess, except one of the four elements. The result of the assessment index score was 34 or 85 percent indicates that there is great potential. It also has determined that the community feedback on plans to promote ecotourism and community participation, which provides an assessment of the needs and the readiness of each part such as: homestay services equal to 3.44 and 2.69 , tour guide services equal 3.51 and 3.03, providing goods services to tourists equal to 3.19 and 2.05. The assessment of the need for assistance from the government to attend activities are: needs support on accommodation equal to 2.00 , needs for a tour guide equal to 2.00 , needs to support the basic construction equal to 2.01, and support to sale souvenir equal to 2.00 .

Factors affecting the plan include promoting ecotourism are: gender and the readiness of the services to provide tour guides, age and the needs of the services to provide accommodation, age and the needs and readiness of the services to provide tour guides, occupation and the needs of the services to provide accommodation, income and the readiness of the services to provide accommodation.

However, factors affecting the adoption plan to promote ecotourism are: gender and the needs and readiness of the services to provide accommodation, gender and the needs of the services to provide tour guides, gender and the needs and readiness of the services for tourists, age and the readiness of the services to provide accommodation, age and the needs and readiness of the services for tourists, education and the needs and readiness of the services to provide accommodation, education and the needs and readiness of the services to provide tour guides, education and the needs and readiness of the services for tourists, occupation and the readiness of the services to provide accommodation, occupation and the needs and readiness of the services to provide tour guides, occupation and the needs and readiness of the services for tourists, income and the needs of the services to provide accommodation, income and the needs and readiness of the services to provide tour guides, and income and the needs and readiness of the services for tourists.

\section{References}

I. Conservation Division. 2001. The List of National Bio-Conservation Area in Laos. Department of Forestry, Ministry of Forestry and Agriculture, Laos

II. Datchanee Aimphan. 2006. Principle of Recreation and Tourism. Teaching Handout, Faculty of Forestry, Kasetsart University, Bangkok.

III. Department of Information, Culture and Tourism. 2007. Tourism Development plan 2007-2010. Department of Information, Culture and Tourism, Bolikhamxai Province, Laos

IV. Environmental Research Institute. 2005. Guideline to Assessment the Quality of Ecotourism Area. Environmental Research Institute, Chulalongkorn University, Bangkok.

V. Krejcie R.V. \& Morgan D R.W. 1970. "Determining Sampling Size for Research Activities". Educational and Psychological Measurement. Vol 30, No.3 Autumn, 607-610.

VI. Forest Research Center. 1995. The Project of Tourism Education to Protected the Ecosystem in South of Thailand. Faculty of Forestry, Kasetsart University, Bangkok. 